\title{
Maternal-Child Exposures to Persistent Organic Pollutants in Dhaka, Bangladesh
}

\author{
Michael Leung ${ }^{1}(\mathbb{1}) \cdot$ Therese Haugdahl Nøst $^{2,3}$ (D) Frank Wania $^{4}\left(\mathbb{D} \cdot\right.$ Eszter Papp $^{1} \cdot$ Dorte Herzke $^{2}$. \\ Abdullah Al Mahmud ${ }^{5}$. Daniel E. Roth ${ }^{1,6}$
}

Received: 8 March 2018 / Revised: 18 July 2018 / Accepted: 20 July 2018 / Published online: 27 July 2018

(c) The Author(s) 2018

\begin{abstract}
Information about the human burdens of persistent organic pollutants (POPs) in low- and middle-income countries is limited. In particular, studies often include only a small subset of POPs. To address this data gap, we aimed to assess maternal-child exposures to POPs in Dhaka, Bangladesh. We quantified 16 organochlorine pesticides, 12 polychlorinated biphenyls, 21 brominated flame retardants, 18 per- and polyfluorinated alkyl substances, 2 polycyclic aromatic hydrocarbons, and short-chain chlorinated paraffins in 18 pooled samples of human cord blood from 90 mother-infant pairs living in Dhaka, Bangladesh (2014-2015). In all pooled samples, we detected high levels of $p, p^{\prime}$-DDT (median $81.6 \mathrm{ng} / \mathrm{g}$ lipid) and its metabolites $p, p^{\prime}$ DDE and $p, p^{\prime}$-DDD (median 551 and $10.7 \mathrm{ng} / \mathrm{g}$ lipid, respectively), where the $p, p^{\prime}$-DDE/ $p, p^{\prime}$-DDT ratio ranged from 2.9 to 9.8 indicating recent dichlorodiphenyltrichloroethane (DDT) exposure. We also detected acenaphthene, decabromodiphenyl ethane, $o, p^{\prime}$-DDT, $o, p^{\prime}$-DDE, hexachlorobenzene, $\beta$-hexachlorocyclohexane, hexabromobenzene, and perfluorooctanoic acid in a subset of samples. For the other 59 target compounds, concentrations were below the limits of detection, despite using ultra-trace analytical methodology. No trends were observed when stratifying the analyses of detected POP concentrations by maternal age, maternal body mass index, or large fish consumption. These findings highlight recent DDT exposure in Dhaka, but the overall POP burden was otherwise low in this sample of pregnant women/newborns. Future monitoring efforts should focus on newly detected POPs for which burdens may be increasing due to ongoing industrialization in Bangladesh.
\end{abstract}

Keywords Child exposure/health $\cdot$ Flame retardants $\cdot$ Perfluorinated chemicals $\cdot$ Pesticides $\cdot$ Polycyclic aromatic hydrocarbons $\cdot$ Analytical methods

Electronic supplementary material The online version of this article (https://doi.org/10.1007/s12403-018-0286-x) contains supplementary material, which is available to authorized users.

Daniel E. Roth

daniel.roth@sickkids.ca

1 Peter Gilgan Centre for Research and Learning, Centre for Global Child Health and SickKids Research Institute, The Hospital for Sick Children, 686 Bay Street, Toronto, ON M5G0A4, Canada

2 Department of Environmental Chemistry, Norwegian Institute for Air Research, Troms $\varnothing$, Norway

3 Department of Community Medicine, The Arctic University of Norway, Troms $\varnothing$, Norway

\section{Introduction}

Persistent organic pollutants (POPs) are a broad class of synthetic chemicals developed for industrial, agricultural, and/ or commercial applications that have known or suspected human toxicity, based on a growing body of animal and epidemiological studies (Baillie-Hamilton 2002; Di Renzo et al.

4 Department of Physical and Environmental Sciences, University of Toronto Scarborough, Toronto, Canada

5 Nutrition and Clinical Services Division, International Centre for Diarrhoeal Disease Research, Bangladesh, Dhaka, Bangladesh

6 Department of Pediatrics, Hospital for Sick Children and University of Toronto, Toronto, Canada 
2015; Diamanti-Kandarakis et al. 2009; Elobeid and Allison 2008; Grant et al. 2014; Liu and Peterson 2015; Loomis et al. 2015; Newbold et al. 2008; Schug et al. 2011; TangPéronard et al. 2011). They can last for years before degrading into less dangerous forms, travel long distances (e.g., through air, water, exported food, commercial products), and bioaccumulate in higher-order animals present in many diets, such as fish which tend to easily enrich POPs in their tissues (Geyer et al. 2000; United Nations Environmental Programme 2005). For these reasons, measures to reduce and/ or eliminate the production and use of POPs were initiated in many countries from the 1970s and onwards, and international regulations like the Stockholm Convention came into place. Although these measures have led to declining human concentrations of many POPs in many high-income countries (Kong et al. 2014), there is scant knowledge of the human burden of exposures in low- and middle-income countries (LMICs), where heavy industrialization and permissive environmental regulations are widespread today.

The Organisation for Economic Co-operation and Development (OECD) has classified hazardous chemicals and waste as a 'red-light' issue (i.e., requiring urgent attention) based on their future projections of environmental trends to 2030 (OECD 2008). Academic societies and international expert workshops have called for further investments into not only the identification of pollutant exposures, but also research on their health effects (Di Renzo et al. 2015; Grandjean et al. 2015). Recent reviews and commentaries have suggested that human exposure to POPs is adversely linked with a diverse array of outcomes that span the lifecourse, including childhood growth and development (Di Renzo et al. 2015; Liu and Peterson 2015; Tang-Péronard et al. 2011), fertility (Di Renzo et al. 2015), pregnancy (Di Renzo et al. 2015), diabetes (Grant et al. 2014), and cancer (Loomis et al. 2015). To date, most epidemiologic studies have focused on 'legacy POPs' including the polychlorinated biphenyls (PCBs) and organochlorine pesticides (OCPs) such as dichlorodiphenyltrichloroethane (DDT), whereas other pollutant groups have not been evaluated in terms of exposure patterns or associations with disease outcomes (World Health Organization 2012), with a notable lack of data from LMICs.

Identifying the relative burden of POPs in populations will help to inform the design of future epidemiologic studies of environmental etiologies of endocrine/metabolic dysregulation and chronic disease. Thus, the specific objectives of this study were to determine the concentrations of OCPs, PCBs, brominated flame retardants (BFRs), per- and polyfluorinated alkyl substances (PFASs), polycyclic aromatic hydrocarbons (PAHs), and short-chain chlorinated paraffins (SCCPs) in umbilical cord blood from a cohort in Dhaka, Bangladesh, and to examine POP concentrations stratified by maternal age, body mass index (BMI), and large fish consumption. Here, umbilical cord blood was the preferred matrix for assessment of maternal-child exposures due to the efficiency of transplacental transmission of POPs (Butler Walker et al. 2003; Covaci et al. 2002; Mazdai et al. 2003; Needham et al. 2011); that is, cord blood concentrations would be indicative of exposures experienced by the mother, as well as by the fetus in utero, a period of particular vulnerability to POP exposures.

\section{Materials and Methods}

\section{Study Area}

This study was based on cord blood samples collected in the Maternal Vitamin D for Infant Growth (MDIG) study trial of 1300 pregnant women in Dhaka, Bangladesh, which has been previously described (Roth et al. 2015). Briefly, the MDIG trial is a randomized, placebo-controlled, doseranging trial of maternal vitamin $\mathrm{D}$ supplementation during pregnancy and lactation on infant length at 1 and 2 years of age. The trial area includes Kamrangirchar, Azimpur, Lalbagh, and Hazaribag, where most of the participants reside in Kamrangirchar-a densely populated group of urban and peri-urban communities located along the Buriganga River in Dhaka.

\section{Participant Selection and Sample Collection}

Of the 1300 pregnant women who were enrolled and actively followed throughout pregnancy in the MDIG trial, 90 were randomly selected for inclusion in this study. Umbilical cord blood collection occurred between July 2014 and October 2015, where from each participant, samples were collected at delivery and stored in $250 \mu \mathrm{l}$ aliquots at the International Center for Diarrhoeal Disease Research, Bangladesh (icddr,b; Dhaka, Bangladesh), then shipped to the Hospital for Sick Children (Toronto, Canada) for specimen processing, and then to the Norwegian Institute for Air Research (Troms $\varnothing$ and Kjeller, Norway) for laboratory analyses. Specimens were shipped on dry ice and stored at $-70{ }^{\circ} \mathrm{C}$ or colder.

\section{Analytical Methodology}

All analyses were performed at the laboratories of the Norwegian Institute for Air Research (NILU). Cord serum samples were extracted and analyzed for OCPs, PCBs, BFRs, PFASs, PAHs, and SCCPs. A complete list of the individual compounds is provided in Online Resource, Table S1. 


\section{Sample Pooling}

Five aliquots of $250 \mu \mathrm{l}$ were pooled (total $1.25 \mathrm{ml}$ per pool) according to selected maternal characteristics believed to influence POP concentrations (Agudo et al. 2009; Ampleman et al. 2015; Axelrad et al. 2009; Bachelet et al. 2011; James et al. 2002; Laden et al. 1999; Pavuk et al. 2014; Quinn and Wania 2012; Sjödin et al. 2014; Tee et al. 2003): maternal age, maternal BMI, and large fish consumption (Table 1). Maternal age was obtained through self-report (tertiles: 18-20, 21-25, 26-40 years), maternal BMI was calculated using maternal weight and height measured at enrolment in the second trimester of pregnancy (tertiles: $<21.5,21.5-25.1,>25.1 \mathrm{~kg} / \mathrm{m}^{2}$ ), and regular large fish consumption (i.e., at least once per week) was determined using data from the MDIG food frequency questionnaire administered at enrolment (Online Resource, Table S2). The primary reason for a pooled analysis was efficiency of stored biological sample use, as it reduced the serum volume requirement from each mother-child pair, allowing for a larger panel of analytes to be performed on all samples than would have been feasible had we analyzed each individual specimen separately.

\section{Extraction and Clean Up}

From each pooled sample $(n=18), 0.225 \mathrm{ml}$ was used for PFAS extractions and the remaining $1.025 \mathrm{ml}$ was used for extractions of all other POPs. The analyses employed the internal standard method for quantification and isotope labeled standards were initially added (Online Resource, Table S3). Briefly, the PFAS analyses were performed using sonication-facilitated liquid-liquid extraction in methanol and activated carbon clean up. Extraction was performed using a method that has been previously described (Hanssen et al. 2013), but with two modifications: (1) the volume methanol $(1000 \mu \mathrm{l})$ added, and (2) the amount of branched perfluorodecanoic acid (br-PFDA) recovery standard (20 $\mu \mathrm{l}$ of $0.102 \mathrm{ng} / \mu \mathrm{l})$.
For the lipid-soluble POPs, the pooled sample was extracted using a method previously described (Nøst et al. 2013). Briefly, deionized water saturated with ammonium sulfate $(1 \mathrm{ml})$, methanol $(2 \mathrm{ml})$, and hexane $(6 \mathrm{ml})$ was added to the sample prior to vortexing and shaking for $1 \mathrm{~h}$. The supernatant organic phase was pipetted off and the extraction protocol was repeated with $6 \mathrm{ml}$ of hexane. The hexane supernatants were combined and evaporated to $0.2 \mathrm{ml}$ in a heated vacuum evaporation unit. The vials were allowed to dry overnight, followed by weighing the next day for gravimetric lipid determination (i.e., lipid \% = dry weight/wet weight $* 100$ ). The residue was resuspended with $0.6 \mathrm{ml}$ hexane by vortexing, before subsequent clean up using Florisil (1 g, deactivated). The samples were eluted from Florisil columns as described previously (Nøst et al. 2013), evaporated to $0.2 \mathrm{ml}$, transferred to a GC-vial, and further reduced to $\sim 30 \mu \mathrm{l}$ by gentle nitrogen flow. Recovery standards (1,2,3,4-tetrachloronaphthalene, carbon-C $\mathrm{C}^{13}$ labeled PCB-159, as well as deuterium labeled biphenyl- $\mathrm{d}_{10}$, fluoranthene- $\mathrm{d}_{10}$, perylene- $\mathrm{d}_{12}$ ) were then added.

\section{Instrumental Analysis}

PFASs were analyzed and quantified by ultrahigh-pressure liquid chromatography triple-quadrupole mass spectrometry as previously described (Hanssen et al. 2013; Nøst et al. 2014). The instrumental details for analyses of OCPs, PCBs, BFRs using gas chromatography combined with mass spectrometry have been previously described (Nøst et al. 2013) with the adaption of a large-volume-injection method of $5 \mu \mathrm{l}$ and the application of a $15 \mathrm{~m} \mathrm{GC}$ column for DDTs and PBDE/DBDPE (decabromodiphenyl ethane), allowing for optimal sensitivity. Corresponding details for analyses of PAHs and SCCPs are presented in Online Resource, Table S4.

Table 1 Pooling scheme for umbilical cord serum samples $(n=90)$ according to maternal age, maternal body mass index (BMI), and large fish consumption

\begin{tabular}{|c|c|c|c|c|c|c|}
\hline \multirow[t]{2}{*}{ Maternal characteristics } & \multicolumn{3}{|c|}{ Irregular/no large fish consumption } & \multicolumn{3}{|c|}{ Regular large fish consumption } \\
\hline & $\mathrm{BMI}<21.5 \mathrm{~kg} / \mathrm{m}^{2}$ & $\begin{array}{l}\text { BMI } 21.5- \\
25.1 \mathrm{~kg} / \mathrm{m}^{2}\end{array}$ & $\mathrm{BMI}>25.1 \mathrm{~kg} / \mathrm{m}^{2}$ & $\mathrm{BMI}<21.5 \mathrm{~kg} / \mathrm{m}^{2}$ & $\begin{array}{l}\text { BMI } 21.5- \\
25.1 \mathrm{~kg} / \mathrm{m}^{2}\end{array}$ & $\mathrm{BMI}>25.1 \mathrm{~kg} / \mathrm{m}^{2}$ \\
\hline Age $18-20$ years & Pool 1 & Pool 2 & Pool 3 & Pool 10 & Pool 11 & Pool 12 \\
\hline Age $21-25$ years & Pool 4 & Pool 5 & Pool 6 & Pool 13 & Pool 14 & Pool 15 \\
\hline Age $26-40$ years & Pool 7 & Pool 8 & Pool 9 & Pool 16 & Pool 17 & Pool 18 \\
\hline
\end{tabular}

Each pool is composed of five $250 \mu \mathrm{l}$ cord blood serum aliquots (total $1.25 \mathrm{ml}$ in each pool). Age was categorized into tertiles: 18-20, 21-25, and 26-40 years. BMI was categorized into tertiles: $<21.5,21.5-25.1,>25.1 \mathrm{~kg} / \mathrm{m}^{2}$. Large fish consumption was categorized into two groups: regular (at least once per week) and irregular/no consumption (less than once per week or no consumption) 


\section{Quality Assurance and Quality Control}

To assess laboratory-derived sample contamination and method accuracy and reproducibility, blanks $(n=4)$ and standard reference materials [SRMs $1958(n=4)$, National Institute of Standards and Technology, Gaithersburg, MD, USA] were processed along with samples. Results for SRMs indicated analytical uncertainties within $60-102 \%$ of assigned values for PCBs, OCPs, BFRs, and within 88-120\% for perfluorooctanoic acid (PFOA) and PFOS. The laboratories at the Norwegian Institute for Air Research routinely participate in the international AMAP ring test for POPs in human serum, and perform well (within $\pm 20 \%$ of assigned values). For PAHs and SCCPs (i.e., compounds that have not been previously assessed in human tissue), SRMs do not exist for quality assurance/quality controls (QA/QCs); and thus, the concentrations should be regarded with some uncertainty.

Recoveries of internal standards were 72-76, 43-86, 78-115, 40-102, and 12-69\% for DDTs, OCPs other than DDTs, PCBs, BFRs, and PAHs, respectively. Compounds for which the recoveries were below $30 \%$ were excluded from the presented results. The limits of detection (LODs) were either software-generated and corresponded to signalto-noise ratios of 3 , or represented three times the concentrations found in blank samples.

\section{Statistical Analysis}

Descriptive summaries of analyte concentrations were presented if the analyte was detected in at least one pooled sample. For analytes detected in at least $9(50 \%)$ of the samples, median (minimum, maximum) values were estimated and further examined by strata defined by maternal age groups (tertiles), maternal BMI category (tertiles), and regular large fish consumption (at least once per week). All statistical analyses were conducted using Stata version 13 (College Station, Texas).

\section{Results}

Characteristics of the participants included in this study are presented in Table 2. Eleven of the 70 compounds were detected in at least one of the 18 pooled umbilical cord blood samples (Table 3). Concentrations of analytes detected in at least 9/18 (50\%) samples, expressed as pg/ml and ng/g lipid, are presented in Table 3. In all samples, we detected high levels of $p, p^{\prime}$-DDT (median $81.6 \mathrm{ng} / \mathrm{g}$ lipid) and its metabolites $p, p^{\prime}$-DDE and $p, p^{\prime}$-DDD (median 551 and $10.7 \mathrm{ng} / \mathrm{g}$ lipid, respectively), where the $p, p^{\prime}$-DDE/ $p, p^{\prime}$-DDT ratio (indicator of recent DDT exposure) ranged from 2.9 to 9.8. Furthermore, in some samples, we detected acenaphthene
Table 2 Characteristics of study participants

\begin{tabular}{ll}
\hline Maternal characteristics $^{\mathrm{a}}$ & $\begin{array}{l}\text { Included partici- } \\
\text { pants }(n=90)\end{array}$ \\
\hline Age (years) & $24(18,35)$ \\
Weight $(\mathrm{kg})$ & $53.9(33.1,81.4)$ \\
Height $(\mathrm{m})$ & $1.51(1.39,1.64)$ \\
BMI $\left(\mathrm{kg} / \mathrm{m}^{2}\right)$ & $23.1(16.1,35.5)$ \\
Regular large fish consumption $^{\mathrm{b}}, n(\%)$ & $45(50.0)$
\end{tabular}

${ }^{a}$ Characteristics are summarized as median (min, max) unless otherwise stated

${ }^{\mathrm{b}}$ Regular consumption refers to self-reported consumption at least once per week at the time of enrolment (second trimester of pregnancy)

(3/18, 17\%), DBDPE (6/18, 33\%), o, $p^{\prime}$-DDT (9/18, 50\%), $o, p^{\prime}$-DDE $(8 / 18,44 \%)$, hexachlorobenzene (HCB) $(6 / 18$, $33 \%), \beta$-hexachlorocyclohexane $(\beta-\mathrm{HCH})(15 / 18,83 \%)$, hexabromobenzene (HBB) $(1 / 18,6 \%)$, and PFOA $(13 / 18$, $72 \%$, Table 3 ). No trends were observed among compounds detected in at least half the samples when stratifying by maternal age, maternal BMI, and regular large fish consumption (Fig. 1). Most of the target compounds (59/70, 84\%) were not detected $(<\mathrm{LOD})$ in any of the 18 pooled samples (Online Resource, Table S5).

\section{Discussion}

We detected $p, p^{\prime}$-DDT and its metabolite $p, p^{\prime}$-DDE (median 81.6 and $551 \mathrm{ng} / \mathrm{g}$ lipid, respectively) in all cord blood samples collected from a recent cohort of mother-infant pairs in Dhaka, Bangladesh. Detection of these compounds was expected, but concentrations were at the lower end of the spectrum of those that have been previously reported in Bangladesh (Bergkvist et al. 2012; Haque et al. 2017; Linderholm et al. 2011; Zamir et al. 2009), where the highest concentrations of $p, p^{\prime}$-DDT and $p, p^{\prime}$-DDE have been previously found in mothers in the rural area of Matlab (median 707 and 2123 ng/g lipid, respectively) (Bergkvist et al. 2012) and garment industry workers in Dhaka (2300 and $2900 \mathrm{ng} / \mathrm{g}$ lipid, respectively) (Zamir et al. 2009). Cross-country comparisons highlight that concentrations in the present cohort are still lower than other countries that endorse DDT use by indoor residual spray to combat malaria, such as South Africa (2788 and 4092 ng/g lipid) (Channa et al. 2012); however, they are still magnitudes higher than those observed in Europe and North America, where production and use of DDT has been eliminated through international regulations like the Stockholm Convention. For example, the median concentrations of $p, p^{\prime}$-DDT and $p, p^{\prime}$-DDE in breast milk from various regions of Norway were 3 and $41 \mathrm{ng} / \mathrm{g}$ lipid, respectively (Polder et al. 2009), while those in North 
Table 3 Concentrations of detected persistent organic pollutants in pooled umbilical cord blood samples $(n=18)$ in Dhaka, Bangladesh

\begin{tabular}{|c|c|c|c|c|c|c|}
\hline \multirow[t]{2}{*}{ Compounds } & \multirow[t]{2}{*}{$>\operatorname{LOD}^{\mathrm{a}}(\%)$} & \multirow[t]{2}{*}{$<$ LOD-max $(\mathrm{pg} / \mathrm{ml})$} & \multicolumn{2}{|c|}{$\begin{array}{l}\text { Wet weight } \\
\text { concentration }{ }^{\mathrm{b}}(\mathrm{pg} / \\
\mathrm{ml})\end{array}$} & \multicolumn{2}{|c|}{$\begin{array}{l}\text { Lipid corrected } \\
\text { concentration }{ }^{\mathrm{b}}(\mathrm{ng} / \mathrm{g} \\
\text { lipid) }\end{array}$} \\
\hline & & & Median & Min, $\max$ & Median & Min, $\max$ \\
\hline \multicolumn{7}{|l|}{ OCPs } \\
\hline$p, p^{\prime}$-DDT & $18(100.0)$ & $15-632$ & 312 & $91.9,632$ & 81.6 & $22.5,204$ \\
\hline$p, p^{\prime}-\mathrm{DDE}$ & $18(100.0)$ & $9-4130$ & 2010 & 739,4130 & 551 & 142,1210 \\
\hline$p, p^{\prime}-\mathrm{DDD}$ & $18(100.0)$ & $12-111$ & 47.9 & $21.1,111$ & 10.7 & $4.2,34.7$ \\
\hline$o, p^{\prime}-\mathrm{DDT}$ & $9(50.0)$ & $10-21.3$ & 7.6 & $5,21.3$ & 2.4 & $0.6,7.3$ \\
\hline$o, p^{\prime}-\mathrm{DDE}$ & $8(44.4)$ & $7-14.2$ & - & - & - & - \\
\hline$p, p^{\prime}-\mathrm{DDE} / p, p^{\prime}-\mathrm{DDT}^{\mathrm{c}}$ & - & - & 6.8 & $2.9,9.8$ & 6.8 & $2.9,9.8$ \\
\hline HCB & $6(33.3)$ & $19.3-24.6$ & - & - & - & - \\
\hline$\beta-\mathrm{HCH}$ & $15(83.3)$ & $15.1-100$ & 33.8 & $7.6,100$ & 9.4 & $1.0,23.9$ \\
\hline \multicolumn{7}{|l|}{ BFRs } \\
\hline HBB & $1(5.6)$ & $28-61$ & - & - & - & - \\
\hline DBDPE & $6(33.3)$ & $134-312$ & - & - & - & - \\
\hline \multicolumn{7}{|l|}{ PAHs } \\
\hline Acenaphthene & $3(16.7)$ & $1830-2240$ & - & - & - & - \\
\hline \multicolumn{7}{|l|}{ PFASs } \\
\hline PFOA & $13(72.2)$ & $37-233$ & 61 & $18.5,233$ & 15 & $2.4,80.3$ \\
\hline
\end{tabular}

${ }^{a}$ Number of samples in which the concentration was above the limit of detection (LOD)

${ }^{\mathrm{b}}$ Values below the LOD were treated as LOD/2

${ }^{\mathrm{c}}$ Ratio of $p, p^{\prime}$-DDE to $p, p^{\prime}$-DDT

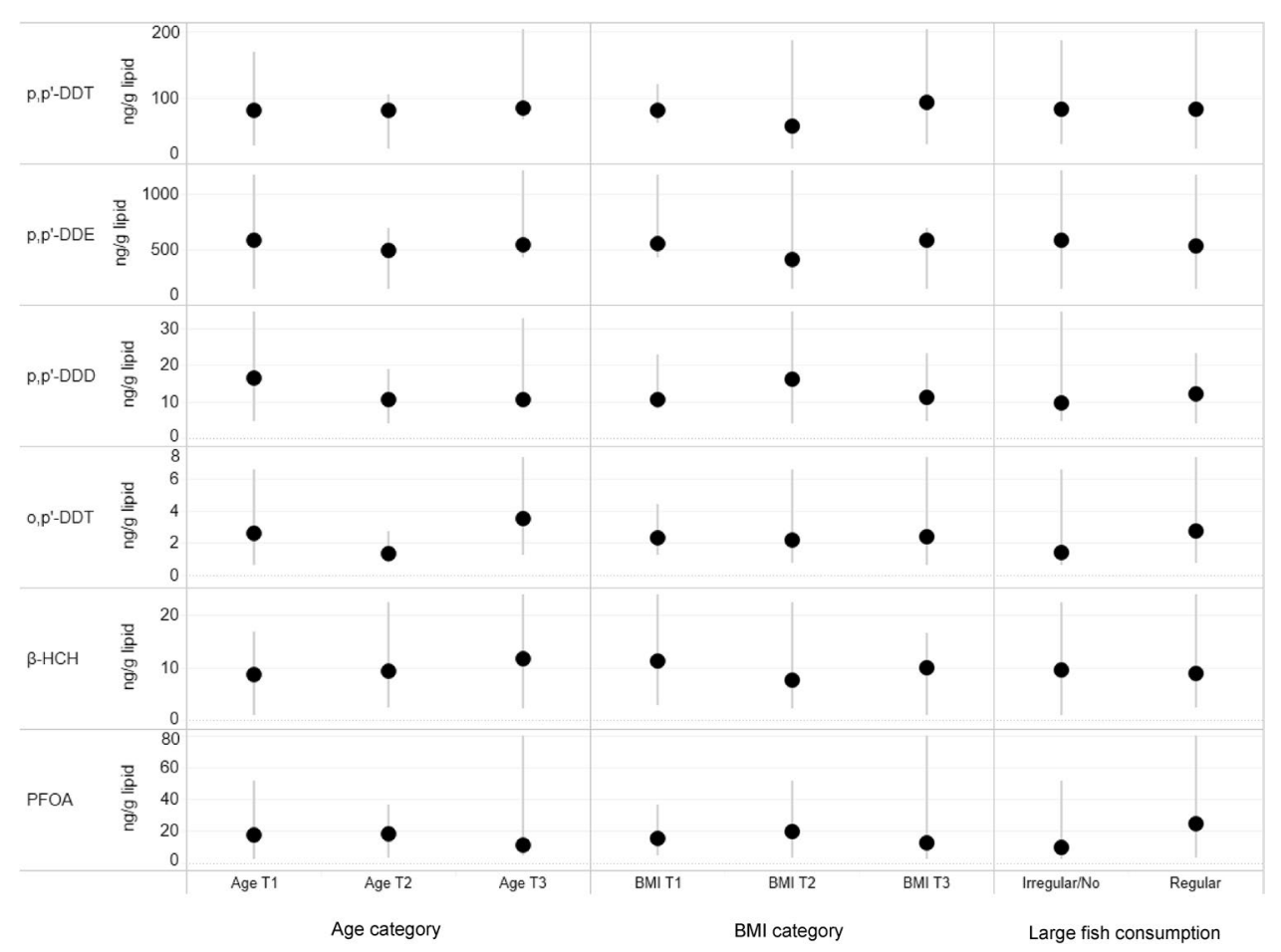

Fig. 1 Trends by maternal age (tertiles), maternal BMI (tertiles), and large fish consumption (regular vs. irregular/ no consumption) for analytes detected in at least $9(50 \%)$ of the samples, where values below the LOD were treated as $0.5 \times$ LOD. Points represent the median concentration (ng/g lipid) in each stratum, and gray bands represent the range of concentrations in each stratum. Age tertiles were T1: 18-20 years, T2: $21-25$ years, and T3: $26-40$ years. BMI tertiles were $\mathrm{T} 1:<21.5 \mathrm{~kg} / \mathrm{m}^{2}, \mathrm{~T} 2$ : $21.5-25.1 \mathrm{~kg} / \mathrm{m}^{2}, \mathrm{~T} 3:>25.1 \mathrm{~kg} /$ $\mathrm{m}^{2}$. Large fish consumption was dichotomized into two groups: regular (at least once per week) and irregular/no consumption (less than once per week or no consumption)
Carolina were 5 and $121 \mathrm{ng} / \mathrm{g}$ lipid, respectively (Pan et al. 2010).

In the present study, the ratio of $p, p^{\prime}$-DDE/ $p, p^{\prime}$-DDT ranged from 2.9 to 9.8 , suggesting that exposure to DDT is either recent or ongoing. For comparison, the median ratio of $p, p^{\prime}$-DDE/ $p, p^{\prime}$-DDT was 55 from recent samples in northern Norway, where DDT use has long been phased out (Nøst et al. 2013); while the ratio of $p, p^{\prime}$-DDE/p, $p^{\prime}$-DDT 
ranged from 1.4 to 2.1 in malaria-endemic regions of South Africa, where the use of DDT is still encouraged for malaria control (Channa et al. 2012). Recent reports have indicated that Bangladesh still has not disposed of their DDT supplies from the 1980s, where improper storage in warehouses has allowed for the contamination of the nearby environment (Illius 2016). Furthermore, DDT continues to be used in Dhaka for the preservation of fish due to its insecticidal properties (Chowdhury et al. 2010), and a recent study showed that the major routes of intake in Bangladesh were food items, particularly beef and fish, as well as house dust (Haque et al. 2017).

We also detected acenaphthene, a by-product of incomplete combustion of organic materials such as natural gas and tobacco (e.g., traffic pollution, cooking, smoking)exposures that are expected to be widespread in Dhaka. Yet, the findings were perplexing as we detected acenaphthene in only three samples, albeit at high concentrations (> $520 \mathrm{ng} / \mathrm{g}$ lipid in three samples) and we cannot exclude analytical uncertainties as the sampling and analyses were not tailored to PAHs in blood. In comparison, a study in Hong Kong reported a median concentration of acenaphthene of $50.3 \mathrm{ng} / \mathrm{g}$ lipid and $67.3 \mathrm{ng} / \mathrm{g}$ lipid in adult men and women, respectively (Qin et al. 2011). Furthermore, we did not find any other PAHs (common co-exposures such as acenaphthylene) in our samples, which could suggest that acenaphthene exposure is inequitably distributed, and perhaps attributable to specific locations within Dhaka or individual behaviors rather than a ubiquitous exposure (e.g., air pollution).

To our knowledge, no prior study of human samples in South Asia has measured DBDPE, a relatively new BFR. Here, we detected DBDPE in six samples (> $28 \mathrm{ng} / \mathrm{g}$ lipid), at levels comparable to those in other industrialized settings. In Guangzhou, one of the largest industrial cities in China, the median concentration of DBDPE in hair samples was found be $17.8 \mathrm{ng} / \mathrm{g}$ lipid (Zheng et al. 2011). In contrast, DBDPE was not detected in human tissue in Canada, New Zealand, and the USA (Mannetje et al. 2013; Petreas et al. 2012; Zhou et al. 2014). The levels observed in some samples in this cohort should be not surprising given that Dhaka is the industrial epicenter of Bangladesh, where it is likely that DBDPE is currently being used as a replacement for decabromodiphenyl ether and octabromodiphenyl ether mixtures-BFRs that are facing increasing regulation and are starting to be phased out of the commercial market due to concerns for environmental and human health (Luo et al. 2010). Given the inconsistent findings (i.e., concerning concentrations in some sample pools, but undetectable in others), further assessment of exposures to brominated compounds should be undertaken in a larger study population in Dhaka.

In addition, we also detected low concentrations of PFOA (surfactant), HCB (pesticide), $\beta$-HCH (insecticide), and
HBB (flame retardant) in a subset of samples. PFOA and $\mathrm{HCB}$ concentrations were similar to those found in India, but much lower than those found in Europe, North America, and South America (Devanathan et al. 2009; Kannan et al. 2004). $\beta$-HCH concentrations (median $9.4 \mathrm{ng} / \mathrm{g}$ lipid) were much lower than previous studies conducted in developed countries such as Germany and Russia, where the median concentrations were found to be 40 and $167 \mathrm{ng} / \mathrm{g}$ lipid, respectively (Lam et al. 2013; Schade and Heinzow 1998). HBB was only detected in one of the pooled samples (the other 17 had values below the LOD), but this finding is difficult to contextualize as we lack data regarding HBB from prior studies in Bangladesh or other countries.

The absence of discernable trends in analyses stratified by maternal age, maternal BMI, and large fish consumption was likely due to a combination of at least five factors: (1) generally low or undetectable concentrations of most of the POPs, (2) sample pooling averaged across five individuals' pollutant concentrations in each stratum, where betweenindividual heterogeneity may have been greater than the between-strata variation, (3) interactions among the three factors (e.g., trends by BMI may differ by age group), (4) lack of consideration of other potentially important predictors of body burden (e.g., beef consumption, concentrations in house dust, Haque et al. 2017), and (5) narrow distributions in maternal age and BMI in our cohort, such that there were only small differences across the strata (Fig. 1).

Overall, several chemicals were detected at low concentrations and in only a subset of samples (with the exception of DDT/DDE), and the majority of compounds we attempted to measure were not detected ( $<$ LOD) in any of the pooled samples, suggesting that the overall human burden of POPs is low in this study population. However, environmental exposures are likely to change due to heavy industrialization in response to growing international trade (Zhang et al. 2017), and poorly regulated management of waste and recycling in Bangladesh. As an example, despite the low levels of PCBs reported in this and other studies in Bangladesh (Bergkvist et al. 2012; Linderholm et al. 2011; Zamir et al. 2009), PCB use in the Bangladeshi energy sector is still widespread (e.g., as coolants/insulating fluids in transformers) (Environment and Social Development Organisation 2005), where the improper disposal or recycling of such electrical equipment may potentially represent future elevated human exposure.

A key strength of this study was the demonstration of the feasibility of measuring a wide array of POPs in relatively small amounts of cord blood $(1.25 \mathrm{ml})$ using state-of-the-art methods to investigate human exposure status in a population for which there is little prior POP data. By revealing the blood burden of a wide range of POPs in this cohort, future pollutant studies in this context can target selected POPs for further examination in large 
population-based studies of these exposures to enable epidemiologic analyses. However, several limitations of this study should be acknowledged. First, the pooling of umbilical cord blood samples did not allow for individuallevel analyses or stratification by variables other than the three we selected prior to pooling (e.g., we could not post hoc consider whether DDT exposure differed by levels of consumption of dried/preserved fish). Second, the ability to detect these chemicals in small sample volumes is limited by the available technology; laboratory methods for some compounds were not tailored for PAHs and SCCPs in human blood and QA/QCs do not include reference materials for these compounds and therefore cautious interpretation of PAH and SCCP concentrations is warranted. Thus, although we may have not detected low background concentrations, we would have captured generally high concentrations in the population. Third, we only considered pollutants that are persistent in the environment, and did not measure other organic pollutants that may be relevant to human health (e.g., Bisphenol A).

In conclusion, our findings confirm that DDT exposure is an ongoing public health concern for mothers and their children in Dhaka, but the overall human burden of the other targeted POPs is low or variable. However, continued monitoring of environmental exposures to POPs will be important as the industrialization of Bangladesh continues. Future research should focus on methods to identify potential sources, environmental transport processes, and routes of uptakes in humans, so that prevention and remediation strategies can be proactively developed to positively impact the population of Bangladesh and other countries similarly undergoing rapid economic development.

Acknowledgements We thank the MDIG Trial Team at the Hospital for Sick Children and the International Centre for Diarrhoeal Disease Research, Bangladesh, MDIG Co-investigators, and Lab Personnel at the Norwegian Institute for Air Research. We also acknowledge the Bill and Melinda Gates Foundation for supporting the original MDIG trial.

Funding This work was supported by The Hospital for Sick Children, Centre for Global Child Health 2016 Catalyst Grant.

\section{Compliance with Ethical Standards}

Conflict of interest The authors declare no conflict of interest.

Ethical Approval All procedures performed in studies involving human participants were in accordance with the Ethical Standards of the Institutional and/or National Research Committee and with the 1964 Helsinki Declaration and its later amendments or comparable ethical standard. For this type of study, formal consent is not required. Analyses of umbilical cord blood specimens were approved by the Research Ethics Board at the Hospital for Sick Children (Canada), and was exempt from Institutional Ethical Review at the Norwegian Institute for Air Research (Norway) and the International Centre for Diarrhoeal Disease Research, Bangladesh (Bangladesh). Data collection and analyses for the original MDIG trial were approved by The
Hospital for Sick Children (Canada) and the International Centre for Diarrhoeal Disease Research, Bangladesh (Bangladesh).

Open Access This article is distributed under the terms of the Creative Commons Attribution 4.0 International License (http://creativeco mmons.org/licenses/by/4.0/), which permits unrestricted use, distribution, and reproduction in any medium, provided you give appropriate credit to the original author(s) and the source, provide a link to the Creative Commons license, and indicate if changes were made.

\section{References}

Agudo A, Goñi F, Etxeandia A, Vives A, Millán E, López R, Amiano P, Ardanaz E, Barricarte A, Chirlaque MD, Dorronsoro M, Jakszyn P, Larrañaga N, Martínez C, Navarro C, Rodríguez L, Sánchez MJ, Tormo MJ, González CA (2009) Polychlorinated biphenyls in Spanish adults: determinants of serum concentrations. Environ Res 109:620-628

Ampleman MD, Martinez A, DeWall J, Rawn DFK, Hornbuckle KC, Thorne PS (2015) Inhalation and dietary exposure to PCBs in urban and rural cohorts via congener-specific measurements. Environ Sci Technol 49:1156-1164

Axelrad DA, Goodman S, Woodruff TJ (2009) PCB body burdens in US women of childbearing age 2001-2002: an evaluation of alternate summary metrics of NHANES data. Environ Res 109:368-378

Bachelet D, Truong T, Verner M-A, Arveux P, Kerbrat P, Charlier C, Guihenneuc-Jouyaux C, Guénel P (2011) Determinants of serum concentrations of 1,1-dichloro-2,2-bis( $p$-chlorophenyl) ethylene and polychlorinated biphenyls among French women in the CECILE study. Environ Res 111:861-870

Baillie-Hamilton PF (2002) Chemical toxins: a hypothesis to explain the global obesity epidemic. J Altern Complement Med 8:185-192

Bergkvist C, Aune M, Nilsson I, Sandanger TM, Hamadani JD, Tofail F, Oyvind-Odland J, Kabir I, Vahter M (2012) Occurrence and levels of organochlorine compounds in human breast milk in Bangladesh. Chemosphere 88:784-790

Butler Walker J, Seddon L, McMullen E, Houseman J, Tofflemire K, Corriveau A, Weber J-P, Mills C, Smith S, Van Oostdam J (2003) Organochlorine levels in maternal and umbilical cord blood plasma in Arctic Canada. Sci Total Environ 302:27-52

Channa K, Röllin HB, Nøst TH, Odland JØ, Sandanger TM (2012) Prenatal exposure to DDT in malaria endemic region following indoor residual spraying and in non-malaria coastal regions of South Africa. Sci Total Environ 429:183-190

Chowdhury M, Amin-ud-Din M, Malek M, Zaman M (2010) DDT residue and its metabolites in dried fishes of Dhaka City markets. Soil Environ 29:117-121

Covaci A, Jorens P, Jacquemyn Y, Schepens P (2002) Distribution of $\mathrm{PCBs}$ and organochlorine pesticides in umbilical cord and maternal serum. Sci Total Environ 298:45-53

Devanathan G, Subramanian A, Someya M, Sudaryanto A, Isobe T, Takahashi S, Chakraborty P, Tanabe S (2009) Persistent organochlorines in human breast milk from major metropolitan cities in India. Environ Pollut 157:148-154

Di Renzo GC, Conry JA, Blake J, DeFrancesco MS, DeNicola N, Martin JN, McCue KA, Richmond D, Shah A, Sutton P, Woodruff TJ, van der Poel SZ, Giudice LC (2015) International Federation of Gynecology and Obstetrics opinion on reproductive health impacts of exposure to toxic environmental chemicals. Int J Gynecol Obstet 131:219-225 
Diamanti-Kandarakis E, Bourguignon J-P, Giudice LC, Hauser R, Prins GS, Soto AM, Zoeller RT, Gore AC (2009) Endocrine-disrupting chemicals: an Endocrine Society scientific statement. Endocr Rev 30:293-342

Elobeid MA, Allison DB (2008) Putative environmental-endocrine disruptors and obesity: a review. Curr Opin Endocrinol Diabetes Obes 15:403-408

Environment and Social Development Organisation (2005) Country situation report on persistent organic pollutants in Bangladesh. Environment and Social Development Organisation, Dhaka

Geyer HJ, Rimkus GG, Scheunert I, Kaune A, Schramm K-W, Kettrup A, Zeeman M, Muir DCG, Hansen LG, Mackay D (2000) Bioaccumulation and occurrence of endocrine-disrupting chemicals (EDCs), persistent organic pollutants (POPs), and other organic compounds in fish and other organisms including humans. In: Bioaccumulation-new aspects and developments. Springer, Berlin, p 1-166

Grandjean P, Barouki R, Bellinger DC, Casteleyn L, Chadwick LH, Cordier S, Etzel RA, Gray KA, Ha E-H, Junien C, Karagas M, Kawamoto T, Paige Lawrence B, Perera FP, Prins GS, Puga A, Rosenfeld CS, Sherr DH, Sly PD, Suk W, Sun Q, Toppari J, van den Hazel P, Walker CL, Heindel JJ (2015) Life-long implications of developmental exposure to environmental stressors: new perspectives. Endocrinology 156:3408-3415

Grant KL, Carpenter DO, Sly LJ, Sly PD (2014) Environmental contributions to obesity and Type 2 diabetes. J Environ Immunol Toxicol 1:80-91

Hanssen L, Dudarev AA, Huber S, Odland JØ, Nieboer E, Sandanger TM (2013) Partition of perfluoroalkyl substances (PFASs) in whole blood and plasma, assessed in maternal and umbilical cord samples from inhabitants of Arctic Russia and Uzbekistan. Sci Total Environ 447:430-437

Haque R, Inaoka T, Fujimura M, Ahmad AS, Ueno D (2017) Intake of DDT and its metabolites through food items among reproductive age women in Bangladesh. Chemosphere 189:744-751

Illius S (2016) 500 Tonnes of DDT poisoning Ctg air. Independent

James RA, Hertz-Picciotto I, Willman E, Keller JA, Charles MJ (2002) Determinants of serum polychlorinated biphenyls and organochlorine pesticides measured in women from the child health and development study cohort, 1963-1967. Environ Health Perspect 110:617-624

Kannan K, Corsolini S, Falandysz J, Fillmann G, Kumar KS, Loganathan BG, Mohd MA, Olivero J, Van Wouwe N, Yang JH, Aldous KM (2004) Perfluorooctanesulfonate and related fluorochemicals in human blood from several countries. Environ Sci Technol 38:4489-4495

Kong D, MacLeod M, Hung H, Cousins IT (2014) Statistical analysis of long-term monitoring data for persistent organic pollutants in the atmosphere at 20 monitoring stations broadly indicates declining concentrations. Environ Sci Technol 48:12492-12499

Laden F, Neas LM, Spiegelman D, Hankinson SE, Willett WC, Ireland K, Wolff MS, Hunter DJ (1999) Predictors of plasma concentrations of DDE and PCBs in a group of U.S. women. Environ Health Perspect 107:75-81

Lam T, Williams PL, Burns JS, Sergeyev O, Korrick SA, Lee MM, Birnbaum LS, Revich B, Altshul LM, Patterson DGJ, Turner WE, Hauser R (2013) Predictors of serum chlorinated pesticide concentrations among prepubertal Russian boys. Environ Health Perspect 121:1372-1377

Linderholm L, Jakobsson K, Lundh T, Zamir R, Shoeb M, Nahar N, Bergman $\AA$ (2011) Environmental exposure to POPs and heavy metals in urban children from Dhaka, Bangladesh. J Environ Monit 13:2728-2734

Liu Y, Peterson KE (2015) Maternal exposure to synthetic chemicals and obesity in the offspring: recent findings. Curr Environ Health Rep 2:339-347
Loomis D, Guyton K, Grosse Y, El Ghissasi F, Bouvard V, Benbrahim-Tallaa L, Guha N, Mattock H, Straif K, International Agency for Research on Cancer Monograph Working Group, IARC, Lyon, France (2015) Carcinogenicity of lindane, DDT, and 2,4-dichlorophenoxyacetic acid. Lancet Oncol 16:891-892

Luo X, Chen S, Mai B, Fu J (2010) Advances in the study of currentuse non-PBDE brominated flame retardants and dechlorane plus in the environment and humans. Sci China Chem 53:961-973

Mannetje A, Coakley J, Bridgen P, Brooks C, Harrad S, Smith AH, Pearce N, Douwes J (2013) Current concentrations, temporal trends and determinants of persistent organic pollutants in breast milk of New Zealand women. Sci Total Environ 458-460:399-407

Mazdai A, Dodder NG, Abernathy MP, Hites RA, Bigsby RM (2003) Polybrominated diphenyl ethers in maternal and fetal blood samples. Environ Health Perspect 111:1249-1252

Needham LL, Grandjean P, Heinzow B, Jørgensen PJ, Nielsen F, Patterson DG, Sjödin A, Turner WE, Weihe P (2011) Partition of environmental chemicals between maternal and fetal blood and tissues. Environ Sci Technol 45:1121-1126

Newbold RR, Padilla-Banks E, Jefferson WN, Heindel JJ (2008) Effects of endocrine disruptors on obesity. Int J Androl 31:201-208

Nøst TH, Breivik K, Fuskevåg O-M, Nieboer E, Odland JØ, Sandanger TM (2013) Persistent organic pollutants in Norwegian men from 1979 to 2007: intraindividual changes, age-period-cohort effects, and model predictions. Environ Health Perspect 121:1292-1298

Nøst TH, Vestergren R, Berg V, Nieboer E, Odland JØ, Sandanger TM (2014) Repeated measurements of per- and polyfluoroalkyl substances (PFASs) from 1979 to 2007 in males from Northern Norway: assessing time trends, compound correlations and relations to age/birth cohort. Environ Int 67:43-53

Organisation for Economic Co-operation and Development (2008) OECD environmental outlook to 2030. Organisation for Economic Co-operation and Development, Paris

Pan I-J, Daniels JL, Herring AH, Rogan WJ, Siega-Riz AM, Goldman BD, Sjödin A (2010) Lactational exposure to polychlorinated biphenyls, dichlorodiphenyltrichloroethane, and dichlorodiphenyldichloroethylene and infant growth: an analysis of the Pregnancy, Infection, and Nutrition Babies Study. Paediatr Perinat Epidemiol 24:262-271

Pavuk M, Olson JR, Wattigney WA, Dutton ND, Sjödin A, Shelton C, Turner WE, Bartell SM, Bartell S, Carpenter DO, Cash J, Foushee R, Percy A, Frumkin H, Lavender M, Moysich K, Olson J, Rosenbaum P, Silverstone A, Weinstock R (2014) Predictors of serum polychlorinated biphenyl concentrations in Anniston residents. Sci Total Environ 496:624-634

Petreas M, Park J, Wang M, Wan Y, Gui W, Tarrant D, Rhee A, Harwani S (2012) The California Biomonitoring Program: persistent organic pollutants in archived and contemporary serum. Glob NEST J 1:80-85

Polder A, Skaare JU, Skjerve E, Løken KB, Eggesb $\emptyset$ M (2009) Levels of chlorinated pesticides and polychlorinated biphenyls in Norwegian breast milk (2002-2006), and factors that may predict the level of contamination. Sci Total Environ 407:4584-4590

Qin YY, Leung CKM, Lin CK, Leung AOW, Wang HS, Giesy JP, Wong MH (2011) Halogenated POPs and PAHs in blood plasma of Hong Kong residents. Environ Sci Technol 45:1630-1637

Quinn CL, Wania F (2012) Understanding differences in the body burden-age relationships of bioaccumulating contaminants based on population cross sections versus individuals. Environ Health Perspect 120:554-559

Roth DE, Gernand AD, Morris SK, Pezzack B, Islam MM, Dimitris MC, Shanta SS, Zlotkin SH, Willan AR, Ahmed T, Shah PS, Murphy KE, Weksberg R, Choufani S, Shah R, Al Mahmud A (2015) Maternal vitamin $\mathrm{D}$ supplementation during pregnancy and lactation to promote infant growth in Dhaka, Bangladesh (MDIG trial): study protocol for a randomized controlled trial. Trials 16:300 
Schade G, Heinzow B (1998) Organochlorine pesticides and polychlorinated biphenyls in human milk of mothers living in northern Germany: current extent of contamination, time trend from 1986 to 1997 and factors that influence the levels of contamination. Sci Total Environ 215:31-39

Schug TT, Janesick A, Blumberg B, Heindel JJ (2011) Endocrine disrupting chemicals and disease susceptibility. J Steroid Biochem Mol Biol 127:204-215

Sjödin A, Jones RS, Caudill SP, Wong L-Y, Turner WE, Calafat AM (2014) Polybrominated diphenyl ethers, polychlorinated biphenyls, and persistent pesticides in serum from the national health and nutrition examination survey: 2003-2008. Environ Sci Technol 48:753-760

Tang-Péronard JL, Andersen HR, Jensen TK, Heitmann BL (2011) Endocrine-disrupting chemicals and obesity development in humans: a review. Obes Rev 12:622-636

Tee PG, Sweeney AM, Symanski E, Gardiner JC, Gasior DM, Schantz SL (2003) A longitudinal examination of factors related to changes in serum polychlorinated biphenyl levels. Environ Health Perspect 111:702-707

United Nations Environmental Programme (2005) Ridding the world of POPs: a guide to the Stockholm Convention on Persistent Organic Pollutants
World Health Organization (2012) State of the science of endocrine disrupting chemicals-2012. World Health Organization, Geneva

Zamir R, Athanasiadou M, Nahar N, Mamun MIR, Mosihuzzaman M, Bergman A (2009) Persistent organohalogen contaminants in plasma from groups of humans with different occupations in Bangladesh. Chemosphere 74:453-459

Zhang Q, Jiang X, Tong D, Davis SJ, Zhao H, Geng G, Feng T, Zheng B, Lu Z, Streets DG, Ni R, Brauer M, van Donkelaar A, Martin RV, Huo H, Liu Z, Pan D, Kan H, Yan Y, Lin J, He K, Guan D (2017) Transboundary health impacts of transported global air pollution and international trade. Nature 543:705-709

Zheng J, Luo X-J, Yuan J-G, Wang J, Wang Y-T, Chen S-J, Mai B-X, Yang Z-Y (2011) Levels and sources of brominated flame retardants in human hair from urban, e-waste, and rural areas in South China. Environ Pollut 159:3706-3713

Zhou SN, Buchar A, Siddique S, Takser L, Abdelouahab N, Zhu J (2014) Measurements of selected brominated flame retardants in nursing women: implications for human exposure. Environ Sci Technol 48:8873-8880 